Revista Eletrônica do Mestrado em Educação Ambienta1

\title{
O ACESSO Á ÁREAS DE LAZER E A PERCEPÇÃO AMBIENTAL INFANTIL NO MUNICIPIO DO RIO DE JANEIRO, RJ - BRASIL
}

\author{
Daniel Shimada Brotto ${ }^{1}$ \\ Merve Mumcu $^{2}$
}

Resumo: Nesse estudo, amostras de crianças entre 6 e 10 anos foram entrevistadas em três bairros da cidade do Rio de Janeiro. Verificando-se uma forte relação entre o brinquedo favorito e o Índice de desenvolvimento Social (IDS) do bairro da habitação da criança. Os brinquedos eletrônicos foram a preferência no bairro com IDS mais alto e a maior frequência de crianças com percepções antropocêntricas ocorreu nesse bairro. Ocorreram frequências mais altas de crianças manifestando percepção ambiental mais integral entre as que brincam com seus pais. Verificando-se que a construção da percepção ambiental das crianças está diretamente relacionada à aspectos de seu ambiente e grupo social, observando-se que quanto mais a criança ocupa seu tempo com atividades lúdicas na natureza, se torna mais conscientes de seu papel no seu meio ambiente.

Palavras-chave: brincadeiras, perfil socioeconômico, percepção ambiental infantil.

\section{EL ACCESO A ÁREAS DE OCIO Y LA PERCEPCIÓN AMBIENTAL INFANTIL EN EL MUNICIPIO DEL RIO DE JANEIRO, RJ - BRASIL}

Resumen: En ese estudio, muestras de niños entre 6 y 10 años fueron entrevistadas en tres barrios de la ciudad de Río de Janeiro. Al ver una fuerte relación entre el juguete favorito y el índice de desarrollo social (IDS) del barrio de la vivienda del niño. Los juguetes electrónicos fueron la preferencia en el barrio con IDS más alto y la mayor frecuencia de niños con percepciones antropocéntricas ocurrió en ese barrio. Se produjeron frecuencias más altas de niños manifestando percepción ambiental más integral entre las que juegan con sus padres. Al ver que la construcción de la percepción ambiental de los niños está directamente relacionada a aspectos de su ambiente y grupo social, observándose que cuanto más el niño ocupa su tiempo con actividades lúdicas en la naturaleza, se vuelve más consciente de su papel en su medio ambiente.

Palabras clave: juegos, perfil socioeconómico, percepción ambiental infantil.

\footnotetext{
${ }^{1}$ Ph.D. em Biociências e Ciências Ambientais na UENF, atuou na docência, e atualmente, pesquisa em ecologia e educação ambiental. Contato: danshima63@gmail.com

${ }^{2}$ Licenciada em C. Biológicas na UVA, foi auxiliar adm. no Col. Belo Futuro Internac., é estagiaria no Lab. de biologia do desenvolvimento da UNIFESP. Contato: mervemumcu.35@gmail.com
} 


\title{
THE ACCESS TO LEISURE AREAS AND CHILDREN ENVIRONMENTAL PERCEPTION IN THE CITY OF RIO DE JANEIRO, RJ - BRAZIL.
}

\begin{abstract}
In this study, samples of children aged 6 to 10 years were interviewed in three districts of the city of Rio de Janeiro. There is a strong relationship between the favorite toy and the Social Development Index (IDS) of the neighborhood housing the child. Electronic toys were the preference in the district with the highest IDS and the highest frequency of children with anthropocentric perceptions occurred in this neighborhood. There were higher frequencies of children manifesting more complete environmental perception among those who play with their parents. It is observed that the construction of children's environmental perception is directly related to aspects of their environment and social group, observing that the more the child occupies his time with playful activities in nature, he becomes more aware of his role in his environment.
\end{abstract}

Key-words: plays, socioeconomic profile, children's environmental perception.

\section{Introdução}

As recentes transformações, tanto em âmbito social quanto em contextos econômicos tem influenciado, inevitavelmente, desde os hábitos familiares até as tradições de uma sociedade. Observando-se mudanças drásticas no desenvolvimento infantil. Considerando-se que o ambiente é conjunto de condições que influenciam a vida social, cultural, moral e também escolar do homem, pode-se perceber que ele é um fator constantemente presente na vivencia humana. Certamente a maior parte do comportamento do indivíduo é constituído a partir das interações com o espaço, mesmo que sejam atividades simples. A vista disso, percebe-se a grande importância do ambiente para o desenvolvimento infantil pois é nele que a criança organiza relações com o mundo e com as pessoas e é ele que será fator determinante na sua formação e sua qualidade de vida. Nesse contexto o ambiente executa um papel importante no desenvolvimento infantil e sendo uma questão fundamental para o desenvolvimento humano.

Como e por que as crianças brincam? Qual a importância disso? "A brincadeira é uma atividade que a criança começa desde seu nascimento no âmbito familiar" (Kishimoto, 2002) e continua com seus parceiros. No início, maioria das vezes ela não tem objetivo educativo ou de aprendizagem pré-definido. A brincadeira possibilita à criança vivenciar o lúdico e descobrir-se a si mesma, aprender a realidade, tornando-se capaz de desenvolver seu potencial criativo (Siaulys, 2005).

Piaget (1987), Vygotsky (1987) procuraram mostrar que a habilidade de conhecer e aprender se constrói a partir das trocas estabelecidas entre o sujeito e o ambiente. Portanto, o desenvolvimento infantil é um processo dinâmico, pois as crianças não são passivas. Elas 
são como receptores das informações presentes ao redor delas. As crianças vão desenvolvendo todas as suas habilidades através das interações com os elementos do seu ambiente, bem como com outras crianças e adultos. A partir dessa reflexão é possível perceber a grande importância do ambiente onde se insere a criança assim como dos brinquedos e das brincadeiras durante o desenvolvimento infantil em todos os aspectos.

Com o advento de pesquisas sobre o desenvolvimento humano, observou-se que o ato de brincar conquistou mais espaço, tanto no âmbito familiar, quanto no educacional no Referencial Curricular Nacional para a Educação Infantil (1998). A brincadeira está colocada como um dos princípios fundamentais, defendida como um direito, uma forma particular de expressão, pensamento, interação e comunicação entre as crianças. Assim, a brincadeira é cada vez mais entendida como atividade que, além de promover o desenvolvimento global das crianças, incentiva a interação entre os pares, a resolução construtiva de conflitos, a formação de um cidadão crítico e reflexivo (Branco, 2005; DeVries, 2003; DeVries \& Zan, 1998; Tobin, Wu \& Davidson, 1989; Vygotsky, 1984, 1987).

Como a criança é um ser em desenvolvimento, sua brincadeira vai se estruturando com base no que é capaz de fazer em cada momento. Isto é, ela aos seis meses e aos três anos de idade tem possibilidades diferentes de expressão, comunicação e relacionamento com o ambiente sociocultural no qual se encontra inserida. Ao longo do desenvolvimento, portanto, as crianças vão construindo novas e diferentes competências, no contexto das práticas sociais, que irão lhes permitir compreender e atuar de forma mais ampla no mundo. Na educação de modo geral, e principalmente na Educação Infantil o brincar é um potente veículo de aprendizagem experiencial, visto que permite, através do lúdico, vivenciar a aprendizagem como processo social.

Conforme as pesquisas da psicologia do desenvolvimento, a maior parte da identidade humana é formada nos primeiros anos da infância (0-12 anos). Sigmund Freud (1995), Erik Erikson (1995), Jean Piaget (1995), analisaram o desenvolvimento humano separando-o em estágios, chegando à conclusão de que o estágio da infância influência outros períodos da vida da pessoa. Por essa razão, a consciência adquirida durante a infância acompanhará o indivíduo por toda a vida.

Trazer a consciência da natureza para as crianças, principalmente no período de 0 a 6 anos de idade, pode significar muito para a formação de uma percepção mais integral. A percepção ambiental pode ser conceituada como uma atividade mental de interação do indivíduo com o meio e o seu estudo é primordial para compreender as inter-relações de 
um dado grupo social com o seu ambiente. Atraves das pesquisas sobre percepçao ambiental de um público alvo, obtém-se resultados que possibilitam criar projetos e atividades pedagógicas com base na realidade deste público, assim, a avaliação da percepção ambiental viabiliza a estruturação de metodologias e estratégias de educação ambiental visando a tomada de consciência diante dos problemas ambientais (Palma 2005). Cabendo citar que essa percepção é fruto de diversos fatores, predominantemente, da educação, que é a forma mais eficaz de sensibilizar o ser humano, pois a medida que se desperta a consciência, pode-se esperar uma atitude transformadora. Para Paulo Freire (1983) a "educação é o desenvolvimento de uma consciência crítica que permite ao homem transformar a realidade".

A partir do que foi acima exposto, percebe-se a importância da Educação Ambiental, quando entendida como um processo contínuo que propicie o despertar da consciência e a aquisição de conhecimentos, valores, habilidades, experiências e determinação para resolver problemas ambientais, buscando uma interação mais harmoniosa entre o ser humano e seu ambiente.

$\mathrm{Na}$ educação de modo geral, e principalmente na Educação Infantil o brincar é um potente veículo de aprendizagem experiencial, visto que permite, através do lúdico, vivenciar a aprendizagem como processo social. Estar em um ambiente natural realizando atividades lúdicas que trabalham criatividade, sensibilização, percepção e a relação dos seres vivos com a natureza são ferramentas fundamentais para (re) construir uma relação ser humano - natureza no pensamento das crianças. No presente trabalho, a hipótese trabalhada é a de que em bairros com diferente disponibilidade de áreas de lazer e facilidades para que as crianças brinquem ao ar livre, essas crianças apresentam diferentes padrões de percepção ambiental. Cabendo lembrar que o índice de desenvolvimento social (IDS) decorre, entre outros fatores, dessa disponibilidade de áreas de lazer e facilidades. Percebendo-se que as grandes cidades não possibilitam oportunidades para contato direto com a natureza pelas crianças, isso é um fator que impede o desenvolvimento de elementos essenciais à uma percepção ambiental que integre o indivíduo ao seu ambiente.

\section{Materiais e métodos}

Por meio de Formulários, foram realizadas entrevistas semiestruturadas com crianças na faixa etária entre 6 e 10 anos no município do Rio de Janeiro, entre os meses de outubro e novembro de 2015. Foram entrevistadas 30 crianças por bairro, sendo 
amostrados os bairros Botafogo, Copacabana e Tijuca, totalizando 89 crianças. Os IDS dos bairros foram respectivamente; 0,$733 ; 0,731$ e 0,706 .

As entrevistas foram realizadas em três diferentes colégios que são Colégio Objetivo (Botafogo), Instituto Superior de Educação do Rio de Janeiro (ISERJ) (Tijuca) e Centro Educacional da Criança (Copacabana). As entrevistas em Copacabana e Tijuca foram realizadas pessoalmente com as crianças enquanto no Botafogo, devido a questões administrativas, os formulários foram distribuídos às crianças e posteriormente recolhidos pelos próprios professores. O formulário utilizado consistiu em oito questões abrangendo a caracterização do perfil sócio econômico (sexo, idade, bairro, local de brincar, brinquedo favorito, quem leva para brincar) e questões sobre preferencias e percepção (do que gosta de brincar e o que pensa sobre o meio ambiente), note-se que as questões se referem a opiniões e percepções, o modelo do formulário apresentado no quadro 1 (Anexo).

Foram utilizadas três diferentes categorias para classificação da percepção ambiental manifestada nas respostas obtidas. Essas categorias foram adaptadas da classificação do Reigota (2007). Essa adaptação se fez necessária, visto que quando interpretadas, algumas respostas não pudessem ser classificadas dentro de nenhuma das categorias estipuladas pelo autor supracitado. Destacando-se respostas como "o meio ambiente é bonito", que foi interpretada como percepção positiva do meio ambiente. Por sua vez, respostas como "o meio ambiente é importante para nossa saúde" foram interpretadas como percepção antropocêntrico do meio ambiente. E por fim, as respostas como "o meio ambiente é arvores" ou "a gente tem que cuidar da natureza", foram interpretadas como percepção naturalista do meio ambiente, pois não evidenciam o homem como parte do meio ambiente. Destaca-se que não ocorreram respostas que pudessem ser interpretadas como percepção integradora do meio ambiente. Todas as respostas obtidas foram digitadas em planilha eletrônica para a análise dos dados obtidos tendo em mente a influência do perfil sócio econômico na preferência do lugar e forma de brincar e na percepção ambiental. Foram utilizadas análises de gráficos e testes de quí-quadrado para avaliar-se a significância dos padrões registrados.

\section{Resultados}

\section{Gênero e idade dos componentes das amostras}


Não ocorreram diferenças significantes (Qui-quadrado $=1,63 ; \mathrm{GL}=2 ; p>0,05$ ) entre os bairros para as frequências de meninas e meninos, embora no bairro de Copacabana tenha ocorrido uma maior frequência de meninas (Figura 1a). As idades dos componentes das amostras variaram entre 3 e 10 anos, com médias (+ desvios padrões) de 7,42 (+1,02) anos, no Botafogo, 7,13 (+1,41) anos, em Copacabana e de 8,07 $(+1,14)$ anos, na Tijuca, registrando-se diferenças significativas (ANOVA, $f=4,65 ; \mathrm{p}=0,012$ ) entre esses valores (Figura 1b).
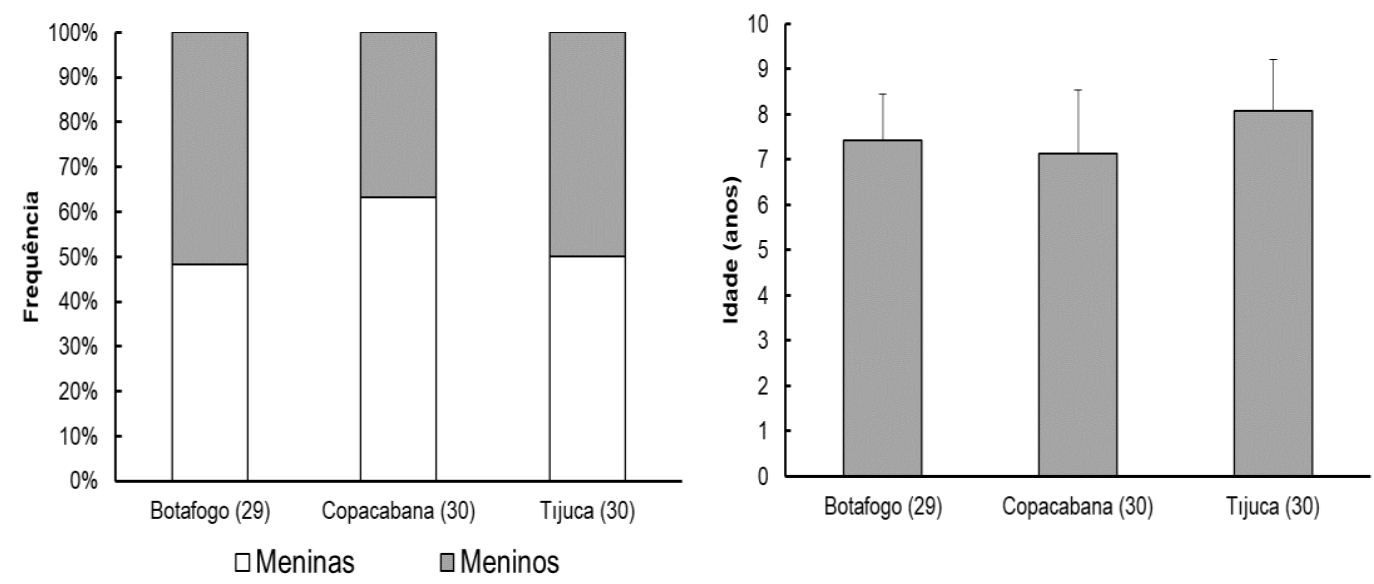

Figura 1: Frequência percentual de meninos e meninas (a) e médias de idade (+ desvios padrões) das amostras (b) de acordo com o bairro.

\section{Locais de brincadeira e suas preferências}

Não ocorreram diferenças significantes (Qui-quadrado $=2,45 ; \mathrm{GL}=2 ; p>0,05$ ) entre os bairros para as frequências de crianças que responderam brincar ao ar livre ou em ambiente confinado, com maior frequência para as que brincam ao ar livre nos bairros de Copacabana e Botafogo e somente no Botafogo ocorreram crianças que responderam não saber onde brincam (Figura 2a). Também não ocorreram diferenças significantes (Quiquadrado $=1,35 ; \mathrm{GL}=2 ; p>0,05)$ entre frequências de crianças que responderam preferir brincar ao ar livre ou em ambientes confinados, as maiores frequências de crianças que responderam preferir brincar ao ar livre ocorreram nos bairros do Botafogo e Copacabana e, mais uma vez, no Botafogo ocorreram crianças que responderam não saber onde preferem brincar (Figura 2b). 

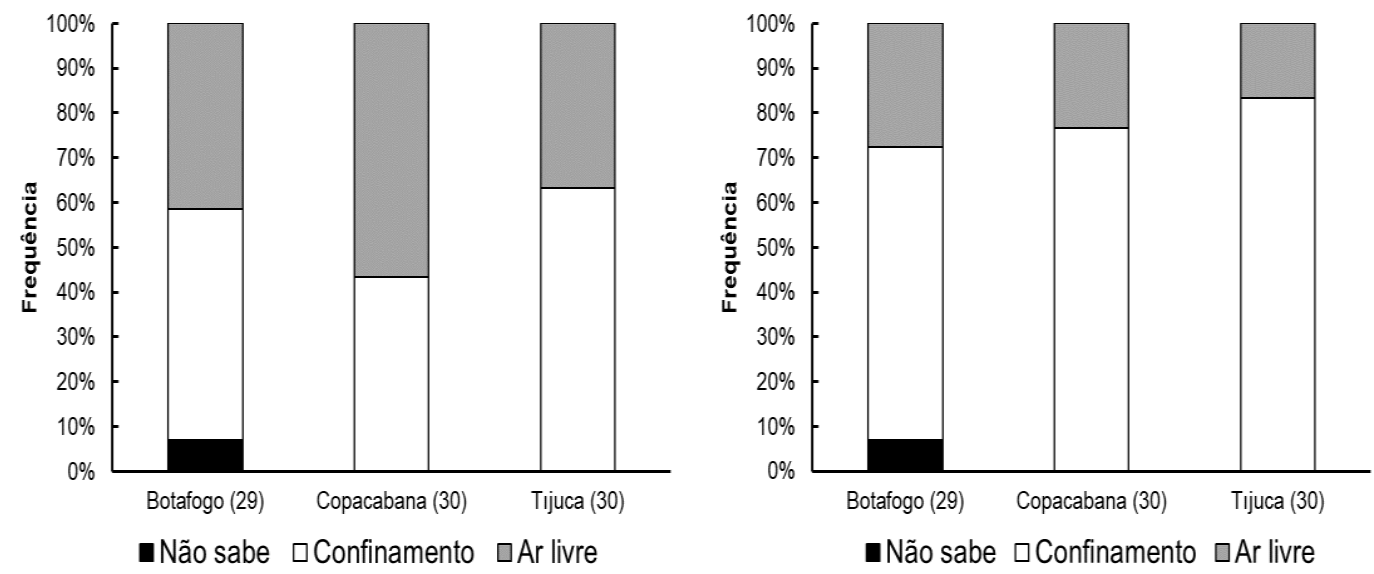

Figura 2: Frequência percentual de respostas sobre o local de brincadeira (a) e o local preferido de brincadeira (b) de acordo com bairros.

\section{Horário de brincadeiras}

Ocorreram diferenças significantes (Qui-quadrado $=15,20 ; \mathrm{GL}=2 ; p<0,01$ ) entre bairros para as frequências de crianças que responderam brincar em horários específicos ou não, com maior frequência de crianças que afirmaram brincar em horários específicos nos bairros da Tijuca, seguido de Copacabana e de Botafogo, em Botafogo e Copacabana se verificou a maior frequência de crianças que responderam brincar todos os dias e em todos os bairros ocorreram crianças que não sabem quais os horários em que brincam, com menor frequência na Tijuca (Figura 3).

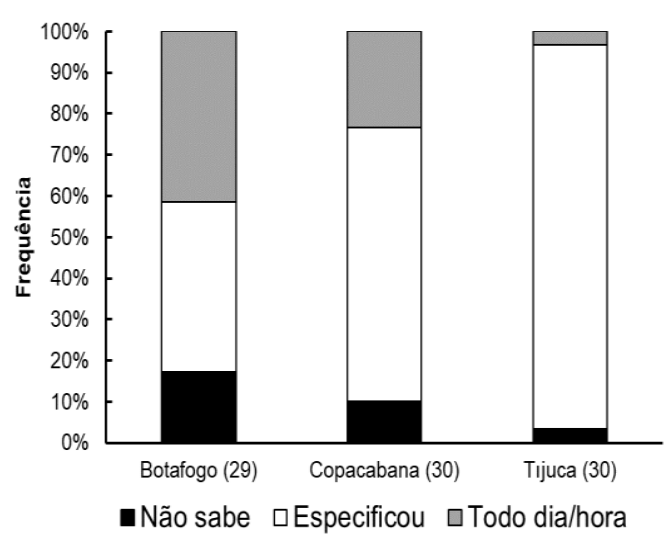

Figura 3: Frequência percentual de respostas sobre o horário em que brincam de acordo com bairros.

\section{Brinquedo favorito}


Ocorreram diferenças significantes (Qui-quadrado $=18,54 ; \mathrm{GL}=2 ; p<0,01$ ) entre as frequências de crianças que responderam brincar com brinquedos eletrônicos ou Convencionais, ocorrendo maior número de crianças que afirmaram preferir brinquedos eletrônicos no bairro do Botafogo, seguido por Tijuca e Copacabana, em Copacabana se verificou a maior frequência de crianças que preferem brincar com brinquedos convencionais, somente no Botafogo ocorreram crianças que não souberam especificar o brinquedo com o qual mais brincam (Figura 4).

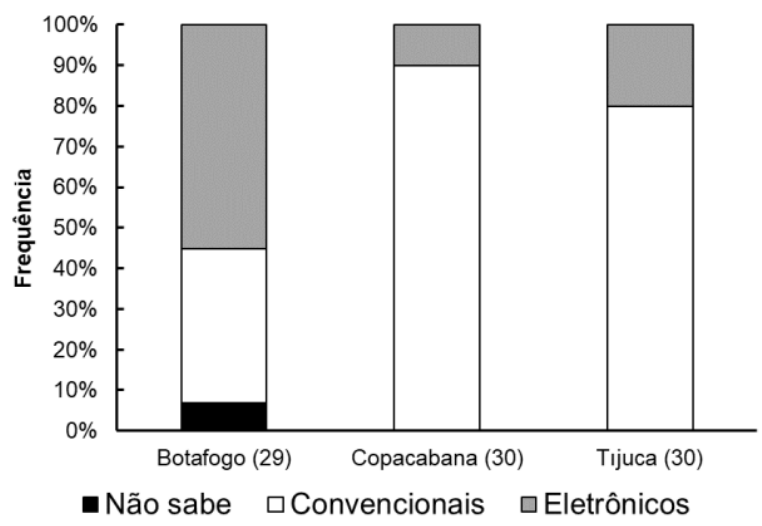

Figura 4: Frequência percentual de respostas sobre o brinquedo favorito de acordo com bairros.

Não ocorreram diferenças significantes (Qui-quadrado $=1,80 ; \mathrm{GL}=2 ; p>0,05$ ) entre as frequências de crianças que responderam brincar com brinquedos eletrônicos ou convencionais de acordo com a idade, ocorrendo número crescente de crianças que afirmaram preferir brinquedos eletrônicos de acordo com as maiores idades (Figura 5).

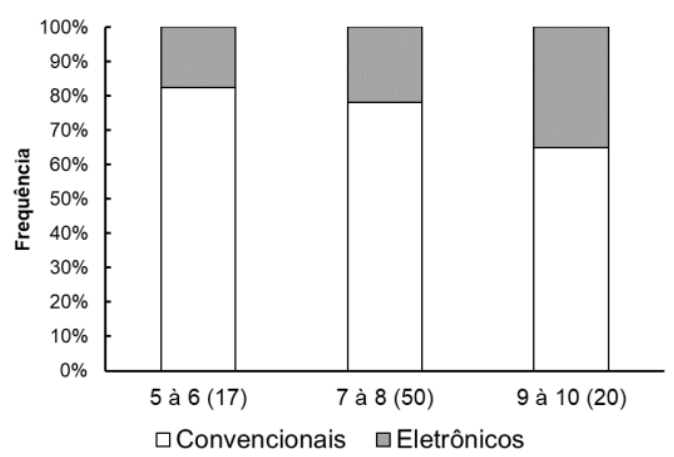

Figura 5: Frequência percentual de respostas sobre o brinquedo favorito de acordo com a idade.

Não ocorreram diferenças significantes (Qui-quadrado $=2,80 ; \mathrm{GL}=2 ; p>0,05$ ) entre as frequências de crianças que responderam brincar com brinquedos eletrônicos ou 
convencionais de acordo com o sexo, ocorrendo maior número de crianças que afirmaram preferir brinquedos eletrônicos para o sexo masculino (Figura 6).

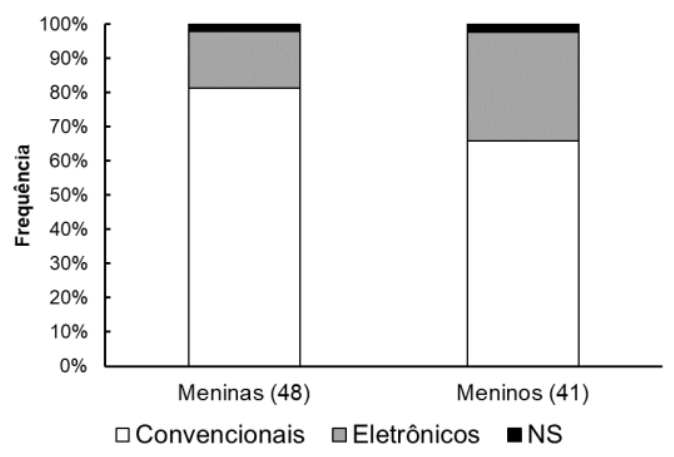

Figura 6: Frequência percentual de respostas sobre o brinquedo favorito de acordo com o sexo.

\section{Acompanhante de brincadeiras}

Ocorreram diferenças significantes (Qui-quadrado $=15,21 ; \mathrm{GL}=2 ; p<0,01$ ) entre os bairros para a frequência de crianças que afirmaram brincar em companhia dos pais ou de outras pessoas, ocorrendo maior frequência de crianças que brincam com seus pais no bairro de Copacabana, seguido por Botafogo e Tijuca, a maior frequência de crianças que responderam brincar à só ocorreu na Tijuca, a frequência de crianças que responderam brincar com parentes foi semelhante entre os bairros do Botafogo e Tijuca e somente no Botafogo ocorreram crianças que responderam brincar com amigos (Figura 7).

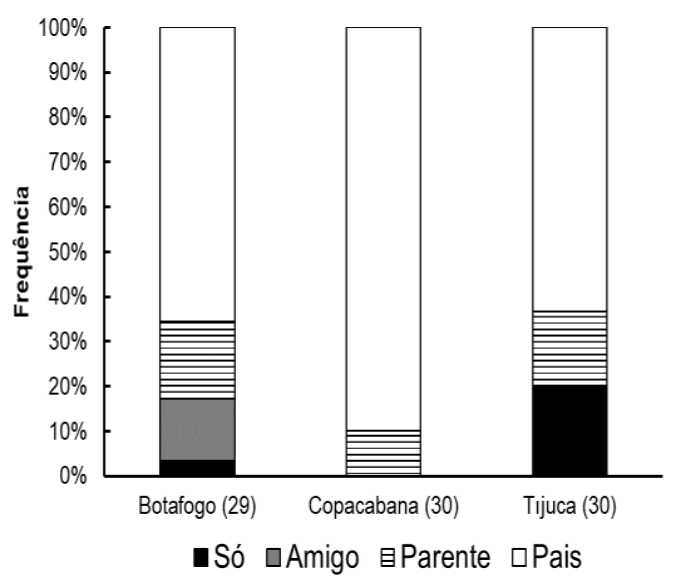

Figura 7: Frequência percentual de respostas sobre o acompanhante de acordo com os bairros.

\section{Percepção ambiental}

Rev. Eletrônica Mestr. Educ. Ambient. Rio Grande, v. 36, n. 2, p. 44 - 59, mai./ago. 2019. 
Ocorreram diferenças significantes (Qui-quadrado $=6,16 ; \mathrm{GL}=2 ; p<0,01$ ) entre os bairros para frequência de respostas que denotassem percepção do meio ambiente da categoria naturalista ou outra. Somente no Botafogo ocorreram respostas que pudessem ser caracterizadas como associadas à uma percepção antropocêntrica do meio ambiente, sendo que nesse bairro essa foi a categoria mais frequente, lá também não se registraram abstenções por desconhecimento, as quais ocorreram de forma idêntica em Copacabana e na Tijuca, as respostas associadas à uma percepção positiva do meio ambiente tiveram frequência crescente de acordo com o menor IDS dos bairros, com maior frequência na Tijuca, por outro lado, a percepção naturalista sobre o meio ambiente foi significativamente mais frequente nos bairros de Copacabana e Tijuca nessa ordem de magnitude (Figura 8).

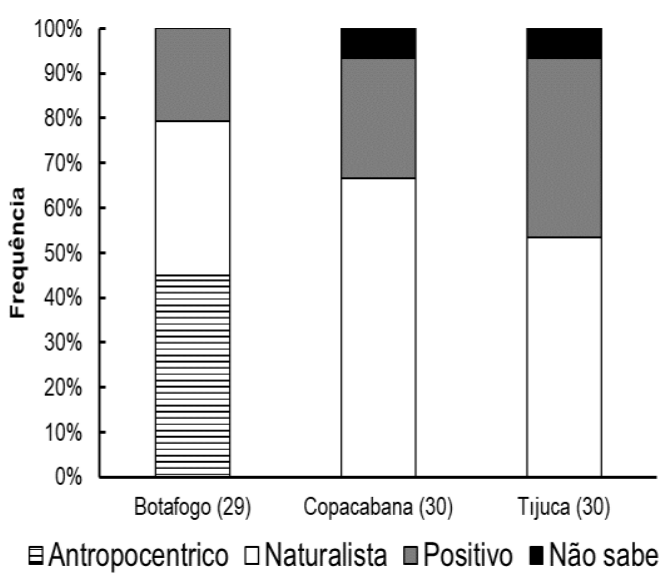

Figura 8: Frequência percentual de respostas sobre a percepção ambiental de acordo com os bairros.

\section{Discussão}

Em artigo escrito por George Monbiot (2012) no jornal britânico The Guardian, o autor analisa os resultados de falta de contato de crianças com a natureza. Segundo o autor a falta de contato de crianças com a natureza pode-se transformar em um problema também para a saúde. No artigo ele levanta a seguinte questão: Como seria possível cuidar ou se preocupar com algo que não conhecemos? Segundo ele os ativistas ambientais muito frequentemente, são pessoas que tiveram uma infância em contato com a natureza. Nesse contexto verifica-se a necessidade de mais investigações sobre como fomentar-se o maior contato das crianças com a natureza, sendo isso essencial para formação de indivíduos com uma percepção que as integre ao meio ambiente. 
A ausência de diferenças significativas entre os bairros, para a proporção entre meninos e meninas, demonstra que a amostra se apresente padronizada quanto à esse parâmetro, não obstante os resultados obtidos para o bairro de Copacabana possam estar associados particularmente ao maior número de meninas na amostra. Os resultados obtidos para a análise da idade entre os bairros, também sugere que os demais resultados possam estar associados à essa variável, uma vez que a média de idade foi mais elevada na Tijuca, seguida do Botafogo e de Copacabana.

Embora não tenham se observado diferenças significativas quanto aos locais de brincadeira e sua preferência pelas crianças entre os bairros, essa análise traz alguma preocupação pelo fato de que praticamente a metade das crianças da amostra tenham respondido não brincar ao ar livre, preocupando mais ainda quando se verifica que essas crianças na maioria prefiram brincar em outros locais que não ao ar livre.

Segundo Louv (2008), ambientes naturais são fundamentais para um desenvolvimento conveniente da criança por que eles incentivam todos os sentidos e integram a brincadeira para a aprendizagem. Por essa razão, quando a criança passa mais tempo em locais confinados terá menos possibilidade de desenvolver competências. Como foi mencionado anteriormente, a percepção ambiental pode ser definida como a atividade mental de interação do indivíduo com o meio. Levando-se em conta o fato de que em nenhum dos bairros se verificou a percepção ambiental do tipo integrada, poderia se deduzir que existe muito por fazer no que tange a ampliação dessa percepção, porém devese considerar o fato de que a amostra seja basicamente composta de crianças, até mesmo admitindo-se erro amostral no caso dos formulários aplicados no bairro do Botafogo.

Quanto ao horário de brincadeiras, percebe-se que a frequência por bairros de crianças que responderam brincar em horários específicos foi inversa ao valor do IDS dos respectivos bairros, demonstrando que o maior IDS propicia maior facilidade para que a criança ocupe o seu tempo com brincadeiras.

As diferenças observadas entre bairros para as frequências de crianças que tenham brinquedos convencionais e não eletrônicos como preferência, podem estar associadas ao poder aquisitivo correspondente à cada bairro, uma vez que o bairro de maior IDS (Botafogo) foi o que apresentou maior frequência de crianças que preferem brinquedos eletrônicos. Conforme os relatos de Paiva \& Costa (2015) e de Chaves (2014) a tecnologia vem ocupando o lugar dos hábitos tradicionais que abrangem a interação física com os indivíduos e o meio ambiente. Essa mudança, foi registrada nos resultados do presente estudo, deduzindo-se uma menor interação das crianças com o meio ambiente e 
consequentemente ocorra menor possibilidade de se construir uma percepção ambiental integrada. Além disso, também no Botafogo, percebe-se que a percepção ambiental do tipo antropocêntrica parece estar vinculada à preferência por brinquedos eletrônicos.

Supõem-se que a maior frequência de crianças com preferência por brinquedos convencionais verificada em Copacabana, esteja associada ao fato deste ser um bairro praiano. Sendo que nesse bairro, a praia, um local pouco apropriado para brinquedos eletrônicos, tenha figurado como um dos locais ao ar livre mais citados pelas crianças. Observa-se que o gênero e a idade também possam estar associados a maior preferência por brinquedos eletrônicos, no caso, essa maior preferência ocorreu entre as crianças mais velhas e os meninos.

As crianças de bairros de maior IDS, no caso Copacabana e Botafogo, apresentaram maior frequência de crianças que afirmaram brincar com seus país, sendo que na Tijuca ocorreu o maior número de crianças que afirmaram brincar sozinhas, certamente isso está associado aos respectivos padrões de vida de cada bairro, assim como o fato de que somente as crianças do bairro do Botafogo, afirmaram brincar com amigos.

Levando em consideração que as percepções naturalista e positivo do meio ambiente foram encontrados com maior frequência nos bairros onde obtiveram-se mais respostas de brincar com pais, supõe-se que as brincadeiras envolvidas com acompanhamento dos pais favorecem e ajudam para que a criança se desenvolva de uma concepção mais completa sobre natureza. Ramos (2012) ao estudar sobre importância dos ensinamentos e do acompanhamento da família na vida da criança e seus efeitos em desenvolvimento educacional verificou que a participação dos pais nas atividades dos filhos contribui muito tanto no desempenho escolar quanto no desenvolvimento de personalidade.

Levando em consideração que pessoas de maior poder de influenciar as sociedades sejam em boa parte provenientes de grupos sociais mais afortunados economicamente, preocupa que somente no bairro de maior IDS, o Botafogo, tenham ocorrido respostas que pudessem ser caracterizadas como associadas à uma percepção antropocêntrica do meio ambiente, sendo lá essa a categoria mais frequente, também não ocorrendo abstenções por desconhecimento, fato verificado de forma idêntica em Copacabana e Tijuca. A maior frequência de respostas associadas às percepções positiva e naturalista do meio ambiente parecem estar associadas ao menor IDS.

Levando-se em consideração os resultados acima mencionados, percebem-se semelhanças com os resultados obtidos por Naim Uzun e Necdet Saglam (2005), Hacettepe 
State University -Turquia, que pesquisaram a influência do perfil sócio econômico na percepção ambiental e o sucesso acadêmico, com 258 alunos do ensino médio, verificando que as percepções mais adequadas sobre meio ambiente foram observadas em alunos do nível socioeconômico intermediário.

\section{Conclusões}

Verificou-se uma forte relação entre o brinquedo favorito e o IDS correspondente ao bairro de moradia da criança, sendo o brinquedo eletrônico, a preferência no bairro de maior IDS, no mesmo bairro, também estaria relacionado a isso a maior frequência de crianças com percepções antropocêntricas do meio ambiente.

Perceberam-se maiores frequências de respostas mais adequadas quanto à percepção do meio ambiente nas crianças que responderam também brincar com seus pais.

No presente trabalho verificou se que a formação da percepção das crianças sobre o meio ambiente está diretamente ligada com aspectos do ambiente e grupo social em que a criança está inserida, observando-se que quanto mais a criança ocupa seu tempo com atividades lúdicas na natureza mais ela desenvolve uma percepção mais adequado sobre o meio ambiente.

\section{Referências}

BASSO, C. M. Algumas Reflexoes Sobre o Ensino Mediado Por Computadores, 2017 disponível em:

https://docs.google.com/viewer?a=v\&pid=sites\&srcid=ZGVmYXVsdGRvbWFpbnxhc3N1 c3NvcmlhYWNhZGVtaWNhYWNhZGVtaWNhfGd4OjRiMGU0MGMxYWE5NDM5Zj M. Acesso em: 3/11/2017.

CRAIDY, Carmen Maria, et al. Educaçao infantil: pra que te quero? Artmed, 2001. Porto Alegre.

CHAVES, I. C. G. 2014. Tecnologıa E Infâncıa: Um Olhar Sobre As Brıncadeiras Das Crianças. http://www.dfe.uem.br/TCC-2014/IsabelleC.G.Chaves.pdf . Acesso em:26/10/2017.

MONBIOT, G. If children lose contact with nature they won't fight for it. Jornal The Guardian, 2012. Disponível em: https://www.theguardian.com/commentisfree/2012/nov/19/children-lose-contact-withnature . Acesso em: 28/10/2017. 
NASCIMENTO, Greicimára S. Do. \& Orth Mara Rúbia Bispo Orth. A influência dos fatores ambıentais no desenvolvımento infantıl. Disponível em

http://www.uricer.edu.br/cursos/arq_trabalhos_usuario/498.pdf . Acesso em 8/10/2017.

NERIS de Queiroz, Norma Lucia, Albuquerque Maciel, Diva, Uchôa Branco, Angela,

Brincadeira e desenvolvimento infantil: um olhar sociocultural construtivista Paidéia [en linea] 2006, disponível em http://www.redalyc.org/html/3054/305423754005/ Acesso em 9/10/2017.

OLIMPIO, Rafael Cardoso, Percepção ambiental de alunos do curso de Ciencias Biologicas -UFRGS/UERGS no Litoral Norte do Rio Grande do Sul. Monografia de graduação Dept $^{\circ}$ de Biologia .2011.

PAIVA, N. Moares Noleto de, Costa J. Da Silva. Influencia De Tecnologia Na Infancia: Desonvolvimento ou Ameaça? Disponível em:

http://www.psicologia.pt/artigos/textos/A0839.pdf. Acesso em 26/10/2017.

PALMA, I.R., Analise de percepçao ambiental como instrumento ao planejamento da educaçao ambiental. 2005 disponivel em : http://www.lume.ufrgs.br/handle/10183/7708. Acesso em: 3/11/2017.

RAMOS, K. Inácio Suhett. A importância da participação da família no desenvolvimento escolar da criança. 2012. Disponível em:

http://www.webartigos.com/artigos/a-importancia-da-participacao-da-familia-nodesenvolvimento-escolar-da-crianca/94380/. Acesso em: 28/10/2017.

REIGOTA, M. Meio ambiente e representaçao social. 7.ed. São Paulo; Cortez (2007). Sayegh, F. As Relações Entre Desenvolvimento e Aprendizagem Para Piaget e Vygotsky, 2006. Disponivel em : http://www.profala.com/artpsico60.htm. Acesso em $3 / 11 / 2017$.

UZUN, N., Sağlam, N. (2005). EFFECT OF SOCIO-ECONOMIC STATUS ON ENVIRONMENTAL AWARENESS AND ENVIRONMENTAL ACADEMIC SUCCESS (1i.U. Journal of Education) 29, 194-202. Disponível em: http://dergipark.ulakbim.gov.tr/hunefd/article/viewFile/5000048683/5000046004 Acesso em $9 / 10 / 2017$ 


\section{Anexo}

Quadro 1: Formulário utilizado na coleta de dados.

\section{Formulário:}

-Sexo (sempre tentando-se manter a proporcionalidade entre meninos e meninas)

-İdade (sempre entre 6 e 10 anos)

-Bairro

-Onde você brinca? E quando?

-Qual seus brinquedos favoritos?

-Gosta de brincar aonde?

-O que pensa sobre o meio ambiente?

-Quem o leva para brincar fora de casa? 